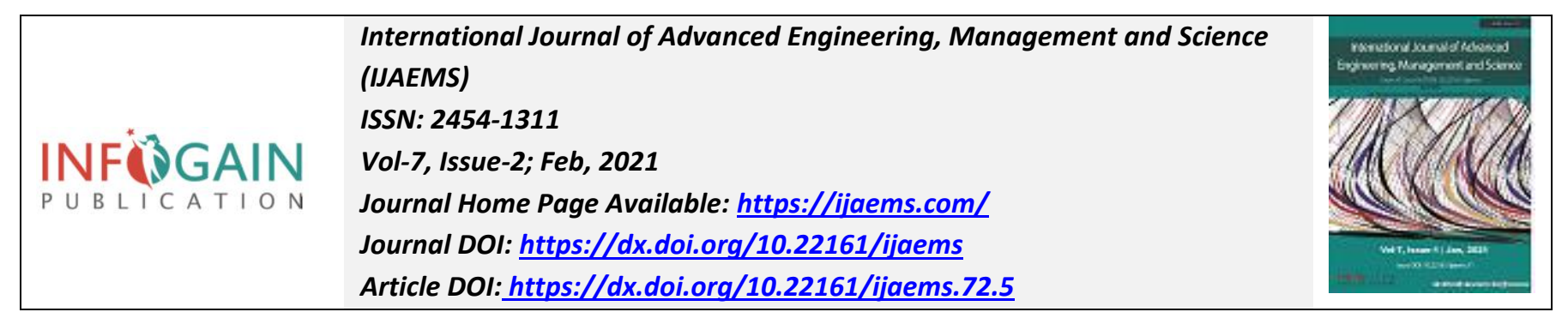

\title{
Research Design of Grounding System for Substation, Using Soil Enhancement Material
}

\author{
Quyen Huy Anh ${ }^{1}$, Hoang Thi Trang 2 , L. T. Nghia ${ }^{1}$, Ly Ngoc Minh ${ }^{3}$, Ly Thi Ngoc Chi ${ }^{4}$, \\ Nguyen Tu Duc ${ }^{1}$
}

\author{
${ }^{1}$ University of Technology and Education HCM City, Viet Nam \\ ${ }^{2}$ Dong Nai Technology University, Viet Nam \\ ${ }^{3}$ Dong Nai College of High Technology, Viet Nam \\ ${ }^{4}$ Cao Thang Technical College, Viet Nam
}

Received: 05 Nov 2020; Received in revised form: 24 Jan 2021; Accepted: 11 Feb 2021; Available online: 28 Feb 2021 (C)2021 The Author(s). Published by Infogain Publication. This is an open access article under the CC BY license (https://creativecommons.org/licenses/by/4.0/).

\begin{abstract}
This paper presents the steps of calculating a safety grounding system of substations as recommended by the IEEE Std standard. 80-2013 with ground grid configuration combined mesh and earth rods, using ground soil enhancement material to reduce ground resistance. A program for automatic design of substation grounding system has been developed, allowing quick calculations to be applied to Electricity companies, Electrical Design Consultants, etc. in Vietnam, for the sample grounding calculation example is applied to the 220/110/22kV Long Thanh substation.
\end{abstract}

Keywords-IEEE 80-2013 standard, grounding system, Soil Enhancement Material, Grounding system design program.

\section{INTRODUCTION}

The effect of grounding in the substation is to facilitate the rapid dissipation of fault currents into the ground in order to minimize local damage as well as avoid their undesirable propagation to other elements of the system while keeping the potentials on the grounding elements at acceptable levels $[2,3,5,6,8]$.

\section{GROUNDING CALCULATION ACCORDING TO IEEE STD. 80-2013}

The IEEE Std 80 - 2013 [1, 4, 7] standard is used for guiding and designing the grounding systems for highvoltage substations meeting safety conditions of grounding resistance as well as step and contact voltages. However, this standard does not cover the soil enhancement material used for reducing grounding resistance when building grounding systems for substations.
Step 1: Determine the grounding area and soil resistivity

The grounding area, in which $a$ is the length and $b$ is the width:

$$
A=a \cdot b\left(m^{2}\right)
$$

Determine soil resistivity at the site where the grounding system is deployed, $\rho(\Omega \mathrm{m})$.

Step 2: Determine the grounding wire section

The grounding wire section:

$$
A_{\text {kcmil }}=I_{f} \cdot \mathrm{K}_{f} \cdot \sqrt{t_{c}}
$$

Where: $A_{\mathrm{kcmil}}$ is the grounding wire section ( $\left.\mathrm{kcmil}\right)$; If is the RMS value of grounding fault current (kA); $t_{c}$ is the time of grounding fault (s); $K_{f}$ is the material coefficient.

Convert cross section of conductor from Akcmil to Amm:

$$
\mathrm{A}_{\mathrm{mm}}=\mathrm{K}_{\mathrm{c}} \cdot \mathrm{A}_{\mathrm{kcmil}}
$$

Where: $\mathrm{K}_{\mathrm{c}}$ is the convert coefficient. 


\section{Step 3: Determine the step and the contact voltages}

-Determine the limit step voltage:

+ For people weighing $50 \mathrm{~kg}$ :

$$
\mathrm{E}_{\mathrm{step50}}=\left(1000+6 \mathrm{C}_{\mathrm{s}} \rho_{\mathrm{s}}\right) \frac{0,116}{\sqrt{t_{s}}}
$$

+ For people weighing $70 \mathrm{~kg}$ :

$$
\mathrm{E}_{\text {step70 }}=\left(1000+6 \mathrm{C}_{\mathrm{s}} \cdot \rho_{\mathrm{s}}\right) \frac{0,157}{\sqrt{t_{s}}}
$$

-Determine the limit contact voltage:

+ For people weighing $50 \mathrm{~kg}$ :

$$
\mathrm{E}_{\text {touch50 }}=\left(1000+1,5 \mathrm{C}_{\mathrm{s}} \cdot \rho_{\mathrm{s}}\right) \frac{0,116}{\sqrt{t_{s}}}
$$

+ For people weighing $70 \mathrm{~kg}$ :

$$
\mathrm{E}_{\text {touch70 }}=\left(1000+1,5 \mathrm{C}_{\text {s. } \rho s}\right) \frac{0,157}{\sqrt{t_{s}}}
$$

Where: $\mathrm{C}_{\mathrm{s}}$ is load reduction factor of the surface layer; $\rho_{\mathrm{s}}$ is resistivity of surface macadam layer $(\Omega \mathrm{m}), \mathrm{t}_{\mathrm{s}}$ is the short circuit duration (s).

\section{Step 4: First design}

At this step, the initial values depend on the type of grounding mesh:

+ Distance between grounding rods D (m);

+ Number of vertical and horizontal bars of the mesh;

+ Total length of the grounding conductors Lc (m);

+ Total length of the grounding rods LR (m);

+ Total length of the grounding conductors and grounding rods $\mathrm{LT}(\mathrm{m})$;

+ Perimeter of grounding mesh LP (m);

+ The depth of the grounding mesh $\mathrm{h}(\mathrm{m})$.

Step 5: Determine the resistance of the grounding system

Determine the resistance of the grounding system:

$$
R_{g}=\rho\left(\left(\frac{1}{L_{T}}\right)+\left(\frac{1}{\sqrt{20 \cdot A}}\right) \cdot\left(1+\frac{1}{\left(1+h \cdot\left(\sqrt{\frac{20}{A}}\right)\right)}\right)\right)
$$

Where: $\mathrm{R}_{\mathrm{g}}$ is the resistance of the grounding $\operatorname{system}(\Omega)$; h is the depth of the grounding mesh $(\mathrm{m}) ; \rho$ is the soil resistivity $(\Omega \cdot \mathrm{m})$; $\mathrm{A}$ is the grounding area $\left(\mathrm{m}^{2}\right)$.

Step 6: Determine the maximum mesh current

$$
\mathrm{I}_{\mathrm{G}}=\mathrm{D}_{\mathrm{f}} \cdot \mathrm{S}_{\mathrm{f}} \cdot 3 \mathrm{I}_{0}
$$

Where: $I_{G}$ is the largest dissipation current to the ground $(\mathrm{A}) ; \mathrm{I}_{0}$ is the zero component of the grounding fault current $(\mathrm{A}) ; \quad \mathrm{D}_{\mathrm{f}}$ is attenuation coefficient; $\mathrm{S}_{\mathrm{f}}$ is segmentation factor of fault current; $I_{g}$ is the grounding fault current (A).

Step 7: Determine the increment of soil potential GPR

The increment of soil potential GPR:

$$
\mathrm{GPR}=\mathrm{I}_{\mathrm{G}} \cdot \mathrm{R}_{\mathrm{g}}
$$

Where: $I_{G}(A)$ is the grounding fault current; $R_{G}$ is the grounding resistance $(\Omega)$.

+ If the GPR value is less than the limited contact voltage, then goes to step 12 , which is the detailed design for the grounding system.

+ If the GPR value is greater than limited contact voltage.

\section{Step 8: Determine the mesh voltage and step voltage}

Determine the distance factor for the mesh voltage Km:

$$
\mathrm{K}_{\mathrm{m}}=\frac{1}{2 \pi} \cdot\left[\ln \left[\frac{D^{2}}{16 \cdot h \cdot d}+\frac{(D+2 \cdot h)^{2}}{8 \cdot D \cdot d}-\frac{h}{4 \cdot d}\right]+\frac{K_{i i}}{K_{h}} \cdot \ln \left[\frac{8}{\pi(2 n-1)}\right]\right]
$$

Where: $\mathrm{D}$ is the distance between the ground wires $(\mathrm{m}) ; \mathrm{h}(\mathrm{m})$ is the depth of the grounding mesh; $\mathrm{d}(\mathrm{m})$ is the grounding wire diameter; $\mathrm{K}_{\mathrm{ii}}$ is adjusting coefficient according to the layout of the grounding mesh; $K_{h}$ is the correction factor for the buried depth of the grounding mesh; $\mathrm{n}$ is geometric coefficient.

For the grounding mesh with ground rods, the mesh voltage Em:

$$
\mathrm{E}_{\mathrm{m}}=\frac{\left(\rho \cdot \mathrm{I}_{G} \cdot \mathrm{K}_{m} \cdot \mathrm{K}_{i}\right)}{L_{c}+\left[1,55+1,22 \cdot\left(\frac{L_{r}}{\sqrt{L_{x}^{2}+L_{y}^{2}}}\right)\right] \cdot L_{r}}
$$

Where: $\rho(\Omega m)$ is the earth resistivity; $I_{G}$ is the maximum earth fault current; $\mathrm{K}_{\mathrm{m}}$ is the distance factor for mesh voltage; $K_{i}$ is the correction factor for the shape of the grounding mesh; $\mathrm{L}_{\mathrm{C}}$ is the total length of the mesh conductors; $\mathrm{L}_{\mathrm{r}}$ is the length of earth rod; $\mathrm{L}_{\mathrm{x}}$ is the mesh length in the $\mathrm{x}$-direction; $\mathrm{L}_{\mathrm{y}}$ is the grid length in the $\mathrm{y}$ direction.

Distance factor for step voltage $\mathrm{K}_{\mathrm{s}}$ :

$$
\mathrm{K}_{\mathrm{s}}=\frac{1}{\pi} \cdot\left[\frac{1}{2 . h}+\frac{1}{D+h}+\frac{1}{D}\left(1-0,5^{n-2}\right)\right]
$$

Step voltage $\mathrm{E}_{\mathrm{s}}$ :

$$
\mathrm{E}_{\mathrm{m}}=\frac{\rho \cdot \mathrm{I}_{G} \cdot \mathrm{K}_{m} \cdot \mathrm{K}_{i}}{0,75 \cdot L_{c}+0,85 \cdot L_{R}}
$$


Where: $L_{R}(m)$ is total length of the earth rods.

Step 9: Compare the mesh voltage Em and the allowable contact voltage $\mathbf{E}_{\text {touch }}$

+ If $\mathrm{E}_{\mathrm{m}} \leq \mathrm{E}_{\text {touch }}$ then goes to Step 10;

+ If $E_{m}>E_{\text {touch }}$ then goes to Step 11 to change the original design.

Step 10: Compare the step voltage Es and the allowable step voltage $\mathbf{E}_{\text {step }}$

+ If $E_{s} \leq E_{\text {step }}$ then goes to Step12. This is the detailed design step;

+ If Es > Estep then goes to Step 11 to change the original design.

\section{Step 11: Change the original design}

If either of the two steps: Step 9 and Step 10 are not satisfied, the original design needs to be changed. Especially, it is possible to change the distance between the grounding conductors (D), the number of earth rods in the grounding mesh $(\mathrm{N})$, the length of each earth rod (Lr), the length of the ground conductors to increase the total value of grounding conductor length (LC), total earth rod length (LR), mesh area ... with the aim of reducing the calculated values of $E_{m}$ and $E_{s}$.

\section{Step 12: Mesh detailed design}

Once all the above steps have been calculated and satisfied, the detailed design of the grounding mesh will be carried out.

\section{CALCULATE GROUNDING RESISTANCE IN CASE OF USING THE GROUND SOIL ENHANCEMENT MATERIAL}

+ Consider a single horizontal electrode with ground soil enhancement material (Fig.1) with the ground resistivity $\rho(\Omega \mathrm{m})$, the grounding resistance $\mathrm{R}$ :

$$
\mathrm{R}=\frac{\rho}{2,73 \cdot L} \log _{10} \frac{2 \cdot L^{2}}{W \cdot D}
$$

Where: $\mathrm{L}$ is the length of horizontal electrode $(\mathrm{m})$; W is the wide of the ground soil enhancement material (m); D is the deep of the groove $(\mathrm{m})$.

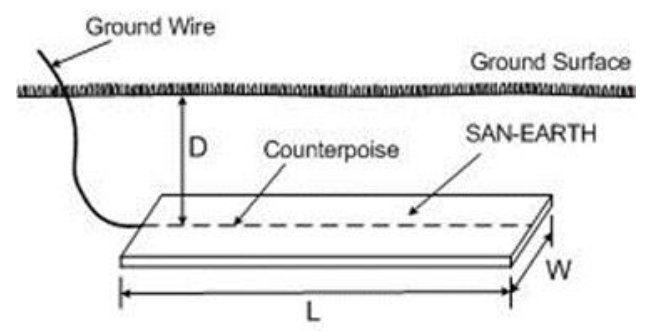

Fig 1. A single horizontal electrode with ground soil enhancement material.
+ Consider two horizontal electrodes with length L (m); deep of electrodes D (m); Distance between 2 electrodes a (m) in Fig. 2, the grounding resistance R:

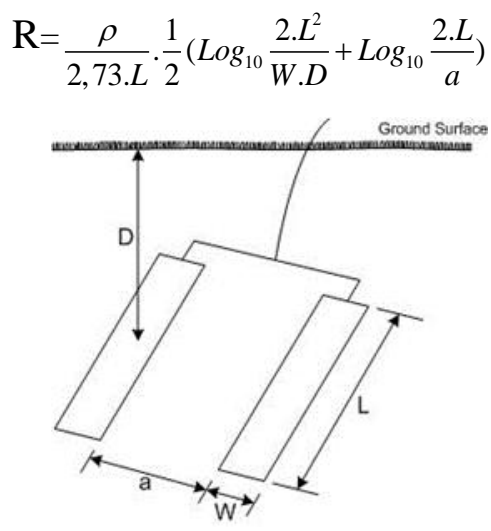

Fig. 2. Two horizontal electrodes with ground soil enhancement material

Consider two strips of ground electrodes placed in an $\mathrm{L}$ shape, each strip has a length $\mathrm{L} / 2(\mathrm{~m})$; wide of strip W (m); Strip deep D (m) in Fig. 3, the grounding resistance $\mathrm{R}$ :

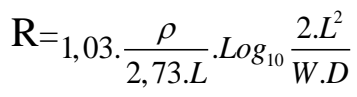

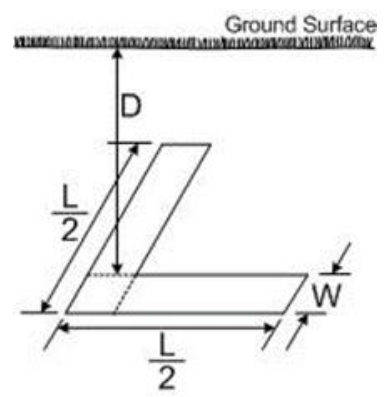

Fig.3. Two strips of ground electrodes placed in an $L$ shape with ground soil enhancement material.

Consider the circumferential ground electrode for 4 square electrode strips with length L/4 (m) (Fig. 4); the grounding resistance $\mathrm{R}$ :

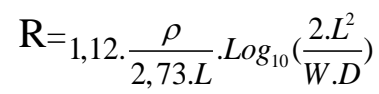




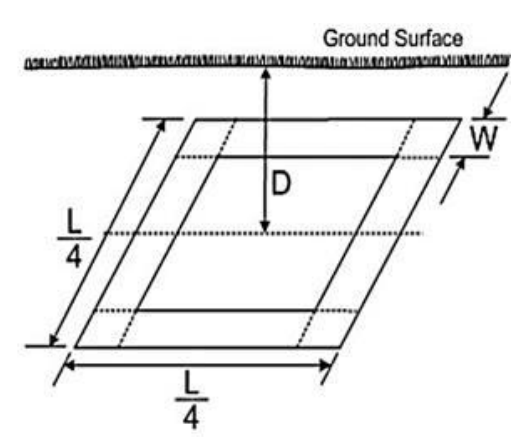

Fig. 4. The circumferential ground electrode.

\section{THE GROUNDING SUBSTATION CALCULATION PROGRAM (GSCP)}

The main functions of the GSCP program include:

+ Automatically design safety grounding mesh for substations whose contact and step voltages are within permissible limits according to IEEE Std 80-2013 in case of using ground soil enhancement material;

+ The grounding mesh configuration uses the horizontal conductors in combination with the vertical grounding rods;

+ Calculate the annual cost function of the proposed grounding mesh in case of using ground soil enhancement material.

\section{a. The initial parameters}

The initial parameters include:

$+t_{f}$ is the grounding fault time (s);

$+Z_{1}$ is the forward equivalent impedance of the primary side $(\Omega)$;

$+Z_{2}=Z_{1}$ is the inverse equivalent impedance of the primary side $(\Omega)$;

$+Z_{0}$ is the zero-equivalent impedance of the primary $(\Omega)$;

$+\mathrm{S}_{\mathrm{f}}$ is the division current factor;

$+\mathrm{V}_{\mathrm{ll}}$ is the phase-to-phase voltage at fault position $(\mathrm{kV})$;

$+\rho$ is the earth resistivity $(\Omega . m)$;

$+\rho_{\mathrm{s}}$ is the resistivity of the surface material layer $(\Omega . m)$;

$+h_{s}$ is thickness of the rock layer (m);

$+\mathrm{h}$ is the deep of grounding mesh (m);

$+h_{0}$ is the deep of referrer grounding mesh (m);

$+\mathrm{Z}_{\mathrm{T} 1}$ is the forward transformer impedance of secondary side $(\Omega)$;
$+\mathrm{Z}_{\mathrm{T} 2}=\mathrm{Z}_{\mathrm{T} 1}$ is the inverse transformer impedance of secondary side $(\Omega)$;

$+\mathrm{Z}_{\mathrm{T} 0}=\mathrm{Z}_{\mathrm{T} 1}$ is the zero-transformer impedance of secondary side $(\Omega)$;

$+\mathrm{S}_{\mathrm{T}}$ is the transformer power (MVA);

$+\mathrm{Z}_{\mathrm{T}}$ is the transformer impedance (\%);

$+\mathrm{V}_{\mathrm{T}_{\text {p pri }} \text { Il }}$ is the primary voltage of transformer $(\mathrm{kV})$;

$+\mathrm{V}_{\mathrm{T}_{-} \text {sec_ }}$ Il is the secondary voltage of transformer $(\mathrm{kV})$;

$+\mathrm{D}_{\mathrm{r}}$ is the grounding mesh wide $(\mathrm{m})$;

$+D_{1}$ is the grounding mesh length (m);

$+\mathrm{W}$ is the soil enhancement material groove width (m);

$+b$ is soil enhancement material groove thickness (m);

$+\mathrm{L}_{\mathrm{r}}$ is the grounding rod length (m);

$+\mathrm{T}_{\mathrm{mt}}$ is the ambient temperature $\left({ }^{0} \mathrm{C}\right)$;

$+\mathrm{T}_{\mathrm{m}}$ is the maximum permissible temperature $\left({ }^{0} \mathrm{C}\right)$;

$+\mathrm{K}_{\mathrm{f}}$ is the material constant;

$+\mathrm{C}_{\mathrm{c}}$ is the cost of $1 \mathrm{~m}$ cooper cable (VND);

$+\Gamma$ is the cost of a Cadweld connector (VND);

$+\mathrm{g}_{\mathrm{r}}$ is the cost of a grounding rod (VND);

$+g_{h}$ is the cost of a soil enhancement material bag (VND);

$+\mathrm{a}_{\mathrm{vh}}$ is the operating factor;

$+\mathrm{T}_{\mathrm{hv}}$ is payback time (Year).

\section{b. Calculation results}

Calculation results include:

$+\mathrm{N}_{\mathrm{r}}$ is the number of bars according to the width;

$+\mathrm{D}_{1}$ is the distance between 2 bars according to width (m);

$+\mathrm{N}_{\mathrm{il}}$ is the number of bars according to the length (m);

$+\mathrm{D}_{2}$ is the distance between 2 bars according to length (m);

$+A_{m}$ is the section of grounding cable $\left(\mathrm{mm}^{2}\right)$;

$+\mathrm{L}_{\mathrm{T}}$ is the total length of grounding cable $(\mathrm{m})$;

$+\mathrm{N}_{\text {rod }}$ is the number of grounding rod;

$+\mathrm{L}_{\mathrm{r}}$ is the length of grounding $\operatorname{rod}(\mathrm{m})$;

$+\mathrm{MH}$ is the total number of Cadweld connector;

$+B_{h}$ is the total number of used soil enhancement material bags (bag);

$+\mathrm{K}$ is the total investment (VND);

$+\mathrm{Z}$ is the calculation annual cost (VND/year). 


\section{GROUNDING CALCULATION FOR 250MVA 220/110KV LONG THANH TRANSFORMER STATION}

Results of the calculation the grounding mesh for the 250MVA 220 / 110kV Long Thanh substation, according to 2 plans: Option 1 - No using soil enhancement material to reduce the grounding resistance and option 2- Using soil enhancement material to reduce the grounding resistance, the results of both plans are presented in Table 1. From analysis the results, it can be found that the two options are similar in terms of economic indicators because the calculation annual cost does not differ by more than $5 \%$.

However, compared to option 1, option 2 has the following advantages:

+ Lower investment;

+ The amount of copper cable and the number of Cadweld welds is lower, which facilitates the installation in the field.

Table. 1. Results of Grounding calculation for Long Thanh 250MVA 220kV/110kV Substaion.

\begin{tabular}{|c|c|c|}
\hline $\begin{array}{l}\text { Calculation } \\
\text { results }\end{array}$ & $\begin{array}{c}\text { Option } 1 \\
\text { No using soil } \\
\text { enhancement } \\
\text { material }\end{array}$ & $\begin{array}{c}\text { Option } 2 \\
\text { Using soil } \\
\text { enhancement } \\
\text { material }\end{array}$ \\
\hline $\begin{array}{l}\text { The number of } \\
\text { bars according to } \\
\text { the width }\end{array}$ & 16 & 11 \\
\hline $\begin{array}{l}\text { The distance } \\
\text { between } 2 \text { bars } \\
\text { according to } \\
\text { width (m) }\end{array}$ & 6,67 & 10 \\
\hline $\begin{array}{l}\text { The number of } \\
\text { bars according to } \\
\text { the length }\end{array}$ & 16 & 11 \\
\hline $\begin{array}{l}\text { The distance } \\
\text { between } 2 \text { bars } \\
\text { according to } \\
\text { length }(\mathrm{m})\end{array}$ & 6.67 & 10 \\
\hline $\begin{array}{l}\text { The section of } \\
\text { grounding cable } \\
(\mathrm{mm} 2)\end{array}$ & 70 & 70 \\
\hline $\begin{array}{l}\text { The total length } \\
\text { of grounding } \\
\text { cable }(\mathrm{m})\end{array}$ & 3000 & 2000 \\
\hline $\begin{array}{l}\text { The number of } \\
\text { grounding rod }\end{array}$ & 56 & 36 \\
\hline The length of & 3 & 3 \\
\hline
\end{tabular}

\begin{tabular}{|l|c|c|}
\hline $\begin{array}{l}\text { grounding rod } \\
(\mathrm{m})\end{array}$ & 256 & 121 \\
\hline $\begin{array}{l}\text { Total number of } \\
\text { Cadweld } \\
\text { connector }\end{array}$ & 0 & 111 \\
\hline $\begin{array}{l}\text { The total number } \\
\text { of used soil } \\
\text { enhancement } \\
\text { material bags } \\
\text { (bag) }\end{array}$ & $062,400,000$ & $703,500,000$ \\
\hline $\begin{array}{l}\text { The total } \\
\text { investment } \\
\text { (VND) }\end{array}$ & $194,040,000$ & $193,460,000$ \\
\hline $\begin{array}{l}\text { The calculation } \\
\text { annual cost } \\
\text { (VND/year) }\end{array}$ & & \\
\hline
\end{tabular}

\section{CONCLUSION}

+ The paper presents the method of calculation and designing the grounding system of substation in two cases, which are not using soil enhancement material and using soil enhancement material, applying the IEEE Std.802013.

+ The research team has developed a GSCP program to calculate and automatically design the safety grounding mesh of the substation to meet technical requirements, and at the same time define a calculated annual cost to selected grounding option plan in both cases with and without using of soil enhancement material.

\section{ACKNOWLEDGEMENTS}

+ The research is processed at the Industrial Electrical Department of Faculty of Electrical and Electronics of Ho Chi Minh city University of Technology and Education.

+ Thank to Power Transmission Company 4- Power Transmission DM 1- 220kV / 110kV Long Thanh station for providing relevant documents and data practically meeting the research results.

\section{REFERENCES}

[1] IEEE Std. 80-2013, IEEE Guide for Safety in AC Substation Grounding.

[2] Muhammad Usman Cheema, MBilal Cheema, Adnan Bashir, M Usman Aslam, A comparison of ground grid mesh design and optimization for $500 \mathrm{kv}$ substation using IEEE 80-2000 and finite element methods, Electrical and Electronics Engineering: An International Journal (ELELIJ) Vol 4, No 1, February 2015. 
[3] Carlos L. B. Silva, Calculation of Grounding Grids Parameter at Arbitrary Geometry, Vol 2, No 2 (2017).

[4] Ho Ninh Thuan, Using soil improvers in calculating safe grounding according to IEEE STD standard. 80-2013, Master thesis, Ho Chi Minh City University of Technical Education, 2016

[5] Akshay Patil, IOSR Journal of Electrical and Electronics Engineering (IOSR-JEEE), Substation Earthing Design, Volume 12, Issue 1 Ver. II, Jan. - Feb. 2017.

[6] Hachimenum Nyebuchi Amadi, Design of grounding system for A.C. substations with critical consideration of the mesh, touch and step potentials, European Journal of Engineering and Technology, Vol. 5 No. 4, 2017.

[7] Tran Nam Anh, Research and calculation of grounding of substations in areas with high soil resistivity, Master of Science Thesis, University of Technical Education, 2019.

[8] Joe Gravelle, P.E. Eduardo Ramirez-Bettoni, P.E., Substation Grounding Tutorial, Minnesota Power Systems Conference Thursday, Nov. 9, 2017. 